\title{
$\mathrm{CC1922}$
}

\section{Wound FRP Shear Reinforcement for Concrete Structures}

Dr Saverio Spadea MEng PhD Ing, Research Fellow, Department of Architecture and Civil Engineering, University of Bath, Bath, BA2 7AY, Fulbright Scholar, Department of Architectural, Environmental and Civil Engineering, University of Miami, USA s.spadea@bath.ac.uk

Dr John Orr MEng(hons) PhD CEng MIStructE FHEA, Lecturer (Assistant Professor) in Civil Engineering, University of Bath, Bath, BA2 7AY

Professor Antonio Nanni PhD PE F.ASCE, Professor and Chair, Department of Architectural, Environmental and Civil Engineering, University of Miami, Coral Gables (FL), USA Yuanzhang Yang BEng Meng, PhD Candidate, Department of Architecture and Civil Engineering, University of Bath, Bath, BA2 7AY

\begin{abstract}
This paper describes the outcomes of recent research that is, for the first time, aiming to completely replace internal steel reinforcement in concrete structures with knitted prefabricated cages made of highly durable fibre reinforced polymer (FRP) reinforcement. The proposed manufacturing technique, based on the filament winding process, allows the reinforcement to be fabricated in a precisely calculated geometry with the aim of providing tensile strength exactly where it is needed. The resulting Wound FRP (W-FRP) cage designs capitalise on the extraordinary flexibility and lightness offered by FRP construction materials. This paper presents fundamental analytical and experimental studies that demonstrate the effectiveness of the wound reinforcement system and forms the basis of future efforts to develop fully automated manufacturing methods for concrete structures.
\end{abstract}


Keywords: fibre reinforced polymer, reinforcement, carbon fibre, filament winding, W-FRP.

\section{INTRODUCTION}

Reinforced concrete (RC) is the most widely used construction material in the world, and the manufacture of cement accounts for at least $5 \%$ of global $\mathrm{CO}_{2}$ emissions (Boden et al. 2013). The fluidity of concrete offers the opportunity to economically create structures of almost any shape, yet RC structures are rarely optimised and, as a result, as much as $40 \%$ of the concrete in a typical building can be wasted (Orr et al. 2014; Thirion 2012). In addition, many RC structures can exhibit poor durability (Ahmad 2003). This can substantially compromise the integrity of RC structures that then need to be repaired or rebuilt to ensure public safety, which can be both costly and inconvenient.

Fibre-reinforced polymer (FRP) reinforcement has been considered as a viable alternative to steel reinforcement since the late 1980s (Plecnik and Ahmad 1988). Over the past two decades, laboratory tests and field applications have demonstrated that FRP bars possess a series of characteristics in addition to corrosion resistance, such as high specific tensile strength and stiffness, that make them appropriate and cost-effective for use in civil engineering applications (Nanni 1993). To date, FRP reinforcing bars have gained some acceptance as internal reinforcement in concrete structures, especially in North America (ACI 440R 2007), but their use is still most common only in specific applications such as bridge decks, traffic barriers, and marine infrastructure.

Unlike steel, which exhibits yielding and plastic flow, FRP reinforcement has a linear elastic stress-strain relationship. The plasticity based design criteria developed for structures with steel reinforcement therefore cannot be directly applied to the design of FRP RC structures. Whilst the scientific community has produced efforts to implement FRP reinforcement into design codes and 
guidelines (AASHTO LRFD 2009; ACI 440.1R 2015; CNR-DT 203 2006; CSA S6 2014; CSA

S806 2012; fib Bulletin 40 2007; JSCE 1997), many research challenges remain as barriers to the widespread use of FRP RC.

FRP is highly anisotropic and is most effectively utilised when loaded in axial tension. Transverse loading relies upon the mechanical properties of the matrix and consequently should be avoided. The Modulus of elasticity of FRP reinforcement is primarily dependent on the stiffness of fibre used in the manufacturing process, and is usually lower than steel. The great success of composite materials, in particular in the aerospace industry, is tied to their high strength-to-weight ratio. Although its combination with concrete makes this aspect irrelevant during the service phase of an FRP reinforced concrete structure, the easy handling of FRP reinforcement cages on site is an important advantage for both health and safety and construction speed.

On the other hand, the advantage of steel reinforcement is that it can be easily bent and shaped at any time, providing a greater range of possibility for the on-site assembly of reinforcement cages. FRP materials cannot be bent or shaped after curing of the resin and therefore any geometrical complexity must be achieved in the plant, before the polymerization process happens. In factory conditions, combining flexible fibres with liquid resin can produce FRP reinforcement of almost any geometry.

This potential has not yet been realised, and FRP bars and stirrups are currently produced in geometries analogous to those of steel reinforcement, despite the two materials possessing completely different mechanical properties. The practice of mimicking steel reinforcement is limiting the construction flexibility and, consequently, the potential for FRP to solve the problem of corrosion of steel reinforcement. The approach of the construction industry to FRP RC to date has thus been to employ the technical knowledge and construction processes derived for steel RC 
structures. This cultural heritage, although very valuable, does not necessarily represent the best way to use the FRP materials as internal reinforcement of concrete structures.

All these issues would suggest looking at FRP RC structures from a different point of view.

The present research aims to explore the possibility of fabricating a novel class of FRP reinforcement in complex geometries, in order to provide tensile strength exactly where the RC structural element needs it. Optimized, lightweight, and durable reinforcing cages will be obtained by winding carbon fibre layers impregnated with resin around pultruded FRP longitudinal reinforcing bars. This will be transformative for concrete construction, greatly simplifying the design of efficient, thin walled and architecturally daring concrete structures.

\section{BACKGROUND ON FRP SHEAR REINFORCEMENT}

Due to their orthotropic nature, the optimal use of fibre-reinforced materials in concrete would require straight reinforcement with tensile stresses acting along the longitudinal axis of the fibres. However, the isostatic lines in concrete members are curved, and shear reinforcement needs bent corners to ensure adequate anchorage. The W-FRP proposed in this paper acts mainly as shear reinforcement. Therefore, the relevant state of the art explored below deals with 1) the strength of curved FRP reinforcement, and 2) the shear strength of FRP reinforced concrete structures.

\section{Strength of curved FRP reinforcement}

FRP shear reinforcement is often produced from pultruded bars prior to resin polymerization in the form of rectangular stirrups for prismatic members (Shehata et al. 2000) or, more rarely, as circular spirals for piers and piles (Ali et al. 2016). Bent portions of such FRP reinforcement experience high shear stresses. During fabrication, the inner fibres of a bar inevitably become kinked as compared to those in the outer radius, causing a significant reduction in the strength capacity of the reinforcement. Experimental results show that FRP stirrups, particularly with 
circular sections, can withstand stresses of approximately $30-80 \%$ of their tensile strength (Ascione et al. 2014; Ishihara et al. 1997; Maruyama et al. 1993; Shehata et al. 2000). The reduction rate is geometrically dependent on the ratio of the bend radius to the bar diameter but it is also influenced by the quality of the manufacturing process, which can determine the degree of fibres kinking. ACI 440.1R (2015) suggests an empirical equation to calculate the design strength of FRP reinforcement at bends, $f_{f b}$, that is adapted from the design recommendation by the (JSCE 1997):

$$
f_{f b}=\left(0.05 \frac{r_{b}}{d_{b}}+0.3\right) \cdot f_{f u} \leq f_{f u},
$$

where $r_{b}$ is the internal radius of the bend, $d_{b}$ is the diameter of the stirrup, and $f_{f u}$ is the tensile strength of the straight reinforcement.

Recent research by Lee et al. (2014) has shown that CFRP stirrups with a rectangular section exhibit improved bend strength as compared to CFRP stirrups with circular sections. The following equation, having a structure similar to Eq. (1), was derived by the same authors on the basis of a linear regression analysis of experimental results:

$$
f_{f b}=\left(0.02 \frac{r_{b}}{d_{f i}}+0.47\right) \cdot f_{f u} \leq f_{f u}
$$

In Eq. (2), $d_{f i}$ is the equivalent diameter of the reinforcement based of the concept of converting the rectangular section to a transformed section composed of a collection of individual circular sections in parallel:

$$
d_{f i} \approx \frac{2}{\sqrt{\pi}} t_{f}
$$

According to the suggested Eq. (3), those circular sections are equivalent to a set of square sections having the side equal to the thickness of the strips, $t_{f}$. 


\section{Shear strength of FRP reinforced concrete structures}

Most FRP design standards calculate the total shear resistance of the member, $V_{r}$, by the addition of a shear reinforcement contribution, $V_{f}$, to the shear strength of the unreinforced concrete section, $V_{c}$. However, the manner in which these two contributions are calculated differ significantly between standards, consequently leading to different predictions of capacity.

The concrete contribution to shear strength $\left(V_{c}\right)$ is calculated in ACI 440.1R (2015) as function of the neutral axis depth, which represents the depth of the cracked concrete, following the work of Tureyen and Frosch (2003). CSA S6 (2014) uses an adjustment of the Modified Compression Field Theory (MCFT) (Vecchio and Collins 1986) for FRP reinforced concrete structures to calculate $V_{c}$ (Hoult et al. 2008), while CSA S806 (2012) proposes an equation specifically derived for FRP reinforced slender beams, accounting for the shear transfer by all mechanisms other than the shear reinforcement (Razaqpur and Isgor 2006).

The contribution to shear capacity of the FRP shear reinforcement $\left(V_{f}\right)$ is calculated in all three above design codes according to the truss analogy:

$$
V_{f}=\frac{A_{f w} f_{f w} d_{w}(\cot \theta+\cot \beta) \sin \beta}{s},
$$

where $\theta$ is the angle of the inclined cracks, $\beta$ is the angle of shear reinforcement with the beam axis, $A_{f w}$ is the area of the shear reinforcement, $f_{f w}$ is the stress level in the FRP shear reinforcement at ultimate, $d_{w}$ is the effective shear depth, and $s$ is the spacing of the reinforcement legs.

All the three methods adopt limitations to the strain level (to control shear crack widths and maintain shear integrity of the concrete) and to the stress level (to avoid failure at the bent portion of the FRP stirrup). Hence, the computation of the ultimate stress level in the FRP shear 
reinforcement follows the format:

$$
f_{f w}=\min \left(\varepsilon_{f w} E_{w}, f_{f b}\right) .
$$

ACI 440.1R (2015) calculates $f_{f b}$ using Eq. (1) and limits the maximum allowed strain in the transverse FRP to $0.50 \%$. CSA S6 (2014) is more conservative: the same method is adopted as in ACI 440.1R (2015) to calculate the FRP strength at bent corners but a 1.5 safety factor is added. An additional equation involving the average axial strain in the beam is suggested in order to calculate the maximum allowed strain in the transverse FRP and this conservatively limited to $0.25 \%$. CSA S 806 (2012) assumes $40 \%$ of the strength of the straight reinforcement as the design strength for bent FRP, with maximum allowed strain in the transverse FRP equal to $0.40 \%$. Although CSA S806 (2012) does not take into account the radius of curvature at corners, it is observed that the 0.4 strength ratio is in agreement with the results of Eq. (1) for recurrent shear reinforcement geometries. It must be emphasized that the maximum permissible strain limitations govern the design of FRP shear reinforcement in most cases.

The three design codes differ in the way that they account for the angle of inclination of diagonal cracks. ACI 440.1R (2015) assumes that diagonal concrete struts will typically occur at $\theta=45^{\circ}$. The assumption is normally justified in practice by the lack of a simple theoretical procedure for accurately determining $\theta$ and also by the empirical observations that a $45^{\circ}$ truss yields conservative results in steel reinforced concrete members. However, this latter argument is not always confirmed by experimental tests specifically conducted on FRP reinforced concrete members, that in many cases have shown very steep inclination of inclined cracks (Razaqpur and Spadea 2015; Said et al. 2016). CSA S6 (2014) uses an adjustment of the MCFT specifically for FRP reinforced concrete structures (Hoult et al. 2008). CSA S806 (2012) provides a simplified equation based on the MCFT for estimating the angle strut angle $\theta$ as function of the longitudinal strain at mid-depth 
of the beam cross section (Razaquur and Spadea 2015).

\section{MATERIALS AND METHODS}

The composites industry employs the automated process of filament winding to produce continuous hollow shapes, generally circular or oval, and having constant cross section. This manufacturing technique consists of winding continuous filaments under tension in predetermined patterns, controlling the fibre feeding mechanisms and the rate of rotation of a mandrel. In the wet winding method, the fibre picks up resin either by passing through a resin bath or from a metered application system. In the dry winding method, the reinforcement is in the pre-impregnated form (pre-preg). After several layers are wound, the component is cured and removed from the mandrel. With the aim of producing a series of reinforcing strips arranged in a variety of orientation rather than continuous hollow shapes, a similar process is manually operated in this study in order to produce FRP shear reinforcement for test specimens. Both the wet and dry winding techniques were considered.

\section{Materials}

Carbon fibres can be manufactured with Modulus of elasticity in the range 150-600 GPa (IUPAC 2014). Standard modulus fibres with a Modulus of elasticity of $240 \mathrm{GPa}$ are commonly used in the manufacturing of civil engineering reinforcement, a choice that provides an appropriate compromise between stiffness and cost. In this work, a continuous 50k carbon fibre tow with a $240 \mathrm{GPa}$ modulus of elasticity (the largest commercially available tow for this class of carbon fibres) was chosen to minimise the number of layers required (Table 1).

In the wet-winding method the Carbon tow is used in combination with a two-component epoxy resin originally designed for the wet-layup of external strengthening to structural members. This class of epoxy resin is applied at room temperature and is air cured, both considerable advantages 
for this application.

In the dry-winding method the same $50 \mathrm{k}$ carbon tow was pre-impregnated by the manufacturer with an epoxy resin with mechanical properties after curing similar to the one used in the wetwinding method. The pre-preg tow facilitates the winding procedure but requires a subsequent curing phase at high temperature and in vacuum conditions. On the other hand this manufacturing process may allow an enhanced quality and durability of the final product resulting in almost total absence of voids and an optimal fibre to resin volume-fraction-ratio of $0.60 / 0.40$. The most relevant technical properties of the two different epoxy resins adopted, as declared by the producers, and the curing method used in the two manufacturing processes are reported in Table 2 .

\section{Experimental Program Overview}

Experimental investigations were performed with the aim of establishing the basis of the production technology for the bespoke reinforcement system. Tensile tests (Series 1) and corner strength tests (Series 2) were undertaken to inform the design of shear critical beam specimens (Series 3), the results and analysis of which are presented in this paper:

- Series 1 - Tensile tests on W-FRP reinforcement:

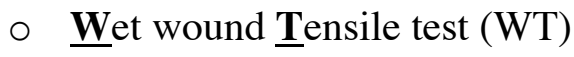

$\circ \quad$ Dry wound $\underline{\text { Tensile test (DT) }}$

- Series 2 - Bent corner strength tests on filament W-FRP reinforcement embedded in concrete:

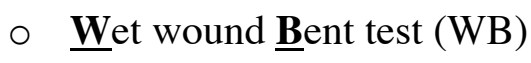

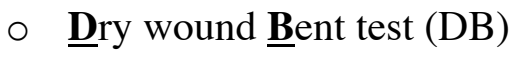

- Series 3 - FRP RC beams with wet wound shear reinforcement 
- Unreinforced in shear (Set I)

- Reinforced in shear with expected shear failure (Set II)

- Reinforced in shear with expected over reinforced flexural failure (Set III)

Series 1 and 2 were used to determine the mechanical properties of the FRP material produced by means of the filament winding technique. The results of Series 1 and 2 informed Series 3, where the effectiveness of the wet wound materials as shear reinforcement for concrete members was established.

\section{Manufacturing}

To perform tensile tests on the straight portions of reinforcement (Series 1) and measure their load capacity at bend locations (Series 2), hand-wound CFRP samples were produced in the form of closed stirrups (Fig. 1). The manufacturing process consisted of winding eight layers of $50 \mathrm{~K}$ carbon tow around rectangular wooden moulds $(850 \mathrm{~mm}$ x $280 \mathrm{~mm})$ with rounded corners. Three different moulds were employed to obtain stirrups with constant width ( $w=6,15$, and $25 \mathrm{~mm})$ and same radius of curvature at corners $\left(r_{b}=15 \mathrm{~mm}\right)$. A Teflon layer was applied to the moulds to facilitate the composite release after curing.

In the wet winding process, each layer of fibre was impregnated with a two component epoxy resin, squeezed with a Teflon tool to remove any excess, and wound around the mould. The stirrups were cured at room temperature for 72 hours, prior to being demoulded. In the dry winding process, the pre-preg tow was wound around the mould, before being packed in a vacuum bag and cured at $120^{\circ} \mathrm{C}$ for 4 hours.

All 8-layer stirrups have a known fibre cross section, $A_{c f}=15.4 \mathrm{~mm}^{2}$, while the total cross sectional area of the reinforcement, $A_{f}$, depends on the fibre to resin volume fraction. As the component densities are known, the resin content was determined by weighing the stirrups, subtracting the 
weight of fibres employed (based on fibre volume and density) and converting the value into a volume. A fiber to resin volume-fraction-ratio of $0.60 / 0.40$ was observed for the dry wound stirrups (confirming the manufacturer's data) while an average volume-fraction-ratio of $0.45 / 0.55$ was measured for the wet wound stirrups.

An equivalent circular diameter, $d_{f e}$, was calculated for each set of rectangular cross section stirrups:

$$
d_{f e}=2 \sqrt{\frac{A_{f}}{\pi}} .
$$

The area-equivalent thickness for each stirrup, $t_{f e}$, was calculated using Eq. (7):

$$
t_{f e}=\frac{A_{f}}{w_{f}} .
$$

A summary of the geometrical properties for each samples produced according to the two manufacturing processes, including equivalent thickness computed on different samples, is reported in Table 3 .

\section{SERIES 1: TENSILE TESTS}

\section{Experiment}

Ten $400 \mathrm{~mm} \times 25 \mathrm{~mm}$ straight samples of reinforcement were obtained from the $25 \mathrm{~mm}$ wide filament wound stirrups to perform tensile tests. Each specimen was $400 \mathrm{~mm}$ long, with a $150 \mathrm{~mm}$ clear distance between aluminium tabs used as grips. The specimen dimensions and test methods follow EN ISO 527-1 (2012) and EN ISO 527-5 (2009), however a different gripping system was adopted.

During pilot tests, using end tabs compliant with EN ISO 527-1 (2012) and EN ISO 527-5 (2009) produced fracture or squashing of the test of the specimens in the grip regions. For this reason, aluminium tabs with a channel rather than flat cross section were used during the tests reported 
here. The channel tabs were specifically designed with purpose of accommodating the cross section of the reinforcement with a $1 \mathrm{~mm}$ layer of adhesive on each adherent surface. Edges of 2 $\mathrm{mm}$ at the sides of the tabs were used to prevent crushing of the specimens (Fig. 2a).

Special attention was dedicated to the preparation of the two adherent surfaces. The inner surface of each aluminium channel was engraved with transverse notches, while the cured CFRP surface was gently sanded. Both surfaces were thoroughly degreased before applying a layer of two components epoxy paste adhesive. Subsequently the specimens were fastened to the tabs with clamps and left for one hour at room temperature. After removing the clamps, they were cured for 24 hours at a temperature of $105^{\circ} \mathrm{C}$, following the manufacturer's recommended curing method. The mid-section of each specimen was instrumented with a uniaxial strain gauge having $10 \mathrm{~mm}$ gauge length bonded onto one flat face of the carbon strip. The opposite face of the specimen was painted with an irregular pattern of black dots on a white background (Fig. 2b), to facilitate later analysis using two-dimensional (2D) Digital Image Correlation (DIC).

In order to improve the adhesive joint performance, a pressure of $10 \mathrm{MPa}$ was passively applied on the first $75 \mathrm{~mm}$ portion of the aluminium tabs controlling the screwing torque on a system of metallic clamps. The specimens were gripped in the testing machine with a pressure of $20 \mathrm{MPa}$ on the $50 \mathrm{~mm}$ end portion of the aluminium tabs. The gripping system adopted allows the level of pressure applied to the aluminium tabs to be controlled and differentiated along the specimen length. The tests were performed in displacement control at $1.0 \mathrm{~mm} / \mathrm{min}$.

High resolution photographs of the samples, perpendicular to the surface under analysis, were collected at each $5 \mathrm{kN}$ load step with the purpose of processing them using DIC. This technique provides full-field displacements and full-field strains by comparing the digital images of a test object surface acquired before and after deformation. A comprehensive review of the 2D DIC 
methodology can be found in Pan et al. (2009).

\section{Predictions}

Considering the mechanical properties of the carbon fibre tow, the expected tensile capacity of eight layers $\left(A_{c f}=15.4 \mathrm{~mm}^{2}\right)$ is $61.6 \mathrm{kN}$. As the resin contribution to tensile strength is negligible, this can be considered the reference tensile capacity for both the wet-wound and dry-wound composite, under the simplifying assumption that all fibres are stressed uniformly up to failure.

However, the CFRP specimens are likely to be subject to uneven distribution of stresses during loading, both due to inaccuracy of the manufacturing process (not all fibres are perfectly straight and aligned to the loading axis) and to the aspect ratio of the specimens (stresses cannot be considered constant along the width). Whereas these effects would be negligible in case of a ductile material due to plastic redistribution, carbon fibres are linear elastic to failure. Consequently, the wound reinforcement is expected to exhibit less than the nominal capacity of the carbon fibres in terms of tensile strength and stiffness.

Knowing the fibre and resin volume fraction ratio and the mechanical properties of the material components, a theoretical calculation of the modulus of elasticity in the direction of fibres is performed according to the mixture law, Eq. (8):

$$
E_{C F R P}=V F_{r} \cdot E_{r}+V F_{f} \cdot E_{c f},
$$

where: $V F_{r}$ is the resin volume fraction, $V F_{f}$ is the fibre volume fraction, $E_{r}$ is the Modulus of elasticity of the resin and $E_{c f}$ is the Modulus of elasticity of the fibre, whose numerical values are reported in Table 1 and Table 2.

Assuming that all fibres are perfectly straight and aligned, the expected modulus of elasticity is therefore equal to 109.7 GPa for the wet wound reinforcement and 145.2 GPa for the dry wound. Whereas the substantial difference in the expected modulus of elasticity is due to the different resin 
contents, the expected axial stiffness $\left(E_{C F R P} A_{f}\right)$ is almost equal in the two cases $(3.75 \mathrm{MN}$ for the wet wound reinforcement and $3.73 \mathrm{MN}$ for the dry wound).

\section{Results and Discussion}

The results of the tensile tests for samples WT and DT are shown in Table 4, with the statistical analysis of the experimental data showing consistency of the experimental setup (full data can be viewed in the data archive, see data access statement for details). The results of the tests performed on the wet wound and the dry wound reinforcement show an average ultimate load of $F_{u, w}=44.9$ $\mathrm{kN}$ and $F_{u, d}=47.9 \mathrm{kN}$, respectively, with very low coefficients of variation $(5 \%$ and $6 \%$, respectively). It can be observed that the use of a pre-impregnated tow rather than a wet-layup process seems to slightly increase efficiency ratio of the fibres referred to full tensile capacity of the fibres (73\% and $78 \%$, respectively).

The modulus of elasticity exhibited by each sample are evaluated by performing a linear regression of the Load-Strain data in the range between the $25 \%$ and the $50 \%$ of the failure load, as suggested in the Annex C of CSA S806 (2012) for pultruded FRP reinforcement (see Table 4). According to this procedure, the wet wound reinforcement exhibited an modulus of elasticity of $E_{C F R P, w}=100.8$ $\mathrm{GPa}\left(92 \%\right.$ of the expected value) whereas the dry wound reinforcement showed a $E_{C F R P, d}=142.0$ GPa modulus of elasticity (98\% of the expected value).

The specific modulus of elasticity of the composite has great relevance in many mechanical and aerospace engineering application, where maximising the stiffness-to-weight ratio is one of the principal purposes of design. As in this case the reinforcement needs to be embedded in a quite heavy material, i.e. concrete, it is more relevant to refer to the actual axial stiffness of the reinforcement. This resulted in being 3.64 MN for the wet wound reinforcement and 3.45 $\mathrm{MN}$ for the dry wound, respectively $97 \%$ and $93 \%$ of the expected values. Again, the use of a pre-preg tow 
seems to reduce the number of kinked fibres and consequently lead to a slight increase of the level of efficiency of the carbon fibres.

Two-dimensional DIC analysis was run using the commercial software MatchID v2016.2 (Lava et al. 2016), employing the approximated Normalized Sum of Squared Differences (NSSD) as correlation technique (Lava et al. 2016). Fig. 2c shows the longitudinal displacements contour map computed on the specimen WT.2 at the incipient failure $(45 \mathrm{kN})$. A generally uniform distribution of displacements along the width of the specimen can be observed.

Overall, the level of improvement of control on the manufacturing process given by the drywinding method does not seem to be remarkable enough to make it preferable, given the number of economical and practical advantages of the wet-winding method.

\section{SERIES 2: BENT CORNER STRENGTH TESTS}

\section{Experiment}

Six CFRP stirrups described in Table 3 were embedded in two $300 \mathrm{~mm} \times 500 \mathrm{~mm} \times 300 \mathrm{~mm}$ concrete blocks as detailed in Fig. 3, according to the testing method suggested in Section B.5 of ACI 440.3R (2012) and Annex F of CSA S806 (2012). Concrete with an average cylinder strength at 28 days of $29.7 \mathrm{MPa}$ (1.13 MPa Standard Deviation), a maximum aggregate size of $20 \mathrm{~mm}$, and a slump equal to $95 \mathrm{~mm}$ was used. The straight portions of the stirrup embedded in block B (see Fig. 3a) were debonded from the concrete by means of a layer of teflon tape treated with debonding agent.

The test setup consisted of a hydraulic jack to apply a relative displacement between the two concrete blocks and a $200 \mathrm{kN}$ load cell to measure applied load. A set of steel plates and rubber pads were installed between the loading device and the two surfaces of the concrete in order to distribute the applied load. 
Each specimen was instrumented with a total of two uniaxial strain gauges installed on the flat side of each leg $\left(\varepsilon_{1}\right.$ and $\left.\varepsilon_{2}\right)$. Displacement transducers on each side of the specimen were used to monitor eccentricity during loading. During testing, block A was mounted on two pins supports and block B was supported by two rollers to minimise the friction forces between the blocks and testing bed. The tests were conducted in laboratory environmental conditions, increasing the force in the jack in a smooth, continuous manner until failure with a loading rate of about $0.5 \mathrm{kN} / \mathrm{s}$.

\section{Results and Discussion}

The experimental results obtained on the wet wound and the dry wound CFRP are shown in Table 5 (full data can be viewed in the data archive, see data access statement for details). All the data refers to test specimens undergoing failure at the bends, on the debonded side of the stirrups. Three different mode of failure are identified as follows: L1) failure of Leg 1 at the bent debonded corner; L2) failure of Leg 2 at the bent debonded corner; S) Simultaneous failure of the two legs at the bent corner.

The ratio $f_{b} / f_{u}$ is calculated on the basis of:

1) the experimental results (Exp.);

2) Eq. (1), in which the area-equivalent diameter (Eq. (6)) is adopted in lieu of the diameter of the circular reinforcement, $d_{b}$ (ACI 440.1R 2015);

3) Eq. (2) (Lee et al. 2014).

As shown in Fig. 4, predictions based on the work of Lee et al. (2014) do not accurately match all of the experimental results. In detail, they are conservative for the wet-wound reinforcement (predicted-to-experimental ratio value equal to 1.27) and slightly unsafe for the dry wound reinforcement (predicted-to-experimental ratio value equal to 0.89). However, considering rectangular stirrups with the same cross sectional area and the same radius of curvature of the 
bends, the strength of the bends increases when a higher width-to-thickness ratio is used. In this sense, the trend indicated Lee et al. (2014) equation can be clearly recognized in the experimental results.

On the other hand, the ACI equation is not able to describe this phenomenon because the areaequivalent diameter (Eq. (6)) is equal for specimens with same cross sectional area but different aspect ratio and leads to a constant $f_{b} / f_{u}$ ratio. As the equation is calibrated on stirrups with circular cross section, the ACI predictions are in general very conservative. The only exception is for WB.06 and DB.06, which have very low aspect ratio $\left(w_{f} / t_{f}\right.$ equal to 1.1 and 1.4 , respectively), and consequently they are geometrically similar to a circular cross section.

The tests conducted on wet wound reinforcement exhibited improved bend strength when compared to their dry-wound counterparts. The main reason for this occurrence could be found in the higher resin content, which may be able to partially carry shear stresses due to bends and thus protect the carbon fibres at the concrete interface.

The results show that the use of wound CFRP reinforcement with high width-to-thickness ratio in lieu of conventional stirrups not only offers a number of advantages in terms of flexibility, but also can help to mitigate the reduction of the strength due to bends. In detail, the WB.25 and DB.25 specimens have shown respectively strength $102 \%$ and $59 \%$ higher than the value that could be expected on circular stirrups, as calculated according to ACI 440.1R (2015).

An electronically controlled system of manufacturing using the wet-wound approach may be able to further enhance the fabrication quality.

\section{SERIES 3: FRP RC BEAMS WITH W-FRP SHEAR REINFORCEMENT}

Test Series 1 and 2 have established the behaviour of bent portions of filament wound FRP materials. From this, Series 3 utilises wet-wound FRP materials to demonstrate the effectiveness 
of the materials as shear reinforcement for concrete members. Four point bending tests were conducted on six concrete beams with CFRP flexural reinforcement. Four beams utilised woven CFRP as shear reinforcement, and two reference specimens were unreinforced in shear.

\section{Experiment}

\section{$\underline{\text { Construction details }}$}

The beams had a rectangular cross section $\left(b_{w}=110 \mathrm{~mm} \times h=220 \mathrm{~mm}\right)$, effective depth, $d=195$ $\mathrm{mm}$ and total length $L=1500 \mathrm{~mm}$ (Fig. 5). Longitudinal flexural reinforcement of 2 \#3 CFRP Aslan 200 rebars (Hughes Brothers 2011) (nominal diameter $D_{f}=10 \mathrm{~mm}$; guaranteed tensile strength $f_{f u l}=2172 \mathrm{MPa}$, modulus of elasticity $E_{f l}=124 \mathrm{GPa}$, total reinforcing area $A_{f l}=142.5$ $\mathrm{mm}^{2}$ ) was used in all specimens. The beams were over reinforced in bending in order to induce a pseudo-ductile mechanism of concrete crushing before FRP rupture in case of flexural failure. The longitudinal FRP reinforcement ratio, $\rho_{l}=0.66 \%$, is more than 3 times the balanced FRP reinforcement ratio, $\rho_{b}=0.20 \%$, (ACI $440.1 \mathrm{R} 2015$ ). The concrete mix was designed to reach a $40 \mathrm{MPa}$ cube strength at 28 days, with $10 \mathrm{~mm}$ maximum aggregate and a slump of between 100 and $150 \mathrm{~mm}$. The average compressive strength measured at 28 days was $43.5 \mathrm{MPa}$ (standard deviation 3.7MPa, from 18 cube specimens of $100 \mathrm{~mm}$ in side length). Assuming a 0.80 cylinder to cube strength ratio (Bamforth et al. 2008), an average concrete strength of $f_{c}=34.8 \mathrm{MPa}$ was considered for calculations.

The specimens were grouped into three sets of identical specimens. The first set (Specimens I.1 and I.2) had no shear reinforcement; the second set (II.1 and II.2) had 3 layers of wound reinforcement ( $A_{f w}=12.8 \mathrm{~mm}^{2}$ per leg); and the third set (III.1 and III.2) had 8 layers of wound reinforcement ( $A_{f w}=34.2 \mathrm{~mm}^{2}$ per leg). The measured fibre to resin volume-fraction-ratio was $0.45 / 0.55$. According to the Series 1 of tests, the wet wound FRP have tensile strength, $f_{C F R P, w}$ and 
modulus of elasticity, $E_{C F R P, w}$, equal to $1313 \mathrm{MPa}$ and $100.8 \mathrm{GPa}$, respectively.

The reinforcement was manufactured using a continuous C T50-4.0/240-E100 carbon tow impregnated with the Fyfe S epoxy resin in a wet-winding process around four longitudinal CFRP bars (Fig. 6). The internal radius of the wound reinforcement at bends was equal to $D_{f l} / 2=5 \mathrm{~mm}$ , whereas the average width of the wound reinforcement was $10 \mathrm{~mm}$ for specimens II.1 and II.2 and $15 \mathrm{~mm}$ for specimens III.1 and III.2, with an average thickness of $1.28 \mathrm{~mm}$ and $3.42 \mathrm{~mm}$ respectively. The wound reinforcement was arranged in two orders of shear reinforcement, one perpendicular to the beam axis and one inclined at $45^{\circ}$ with the beam axis, each of them spaced at $s=180 \mathrm{~mm}$. It should be noted that the manufacturer-applied sand coating gives the longitudinal CFRP bars a whitish appearance, whereas the black colour of the carbon fibres in the W-FRP is emphasized by the epoxy resin.

The cages were cured at room temperature for 72 hours. The two top bars were removed before casting. Neglecting the effect of shear lag, the experimental values of the ultimate stress, $f_{C F R P, w}=$ $1313 \mathrm{MPa}$, and modulus of elasticity, $E_{C F R P, w}=100.8 \mathrm{GPa}$, obtained through the tensile tests on wet-wound reinforcement, were assumed in order to model the mechanical behaviour of the shear reinforcement.

The four point bending tests had a clear span of $1500 \mathrm{~mm}$, and a shear span to depth ratio, $a / d$, of 2.5 (shear span, $a=488 \mathrm{~mm}$ ).

\section{$\underline{\text { Test arrangements }}$}

The four point bending tests (Fig. 5) was set up using two simple supports and two hydraulic jacks attached to a steel frame. The jacks were powered by the same oil circuit and each one was instrumented with a load cell. Three displacement transducers were installed: one at the beam midspan and two at the loading points. The wound reinforcing cages in Set II and III were instrumented 
with three TML FLA-10 uniaxial strain gauges, as shown in Fig. 6b and Fig. 5. After the concrete casting and before performing the tests, the beams were notched on the instrumented side with the aim of driving the location of incipient cracks.

The test were conducted in load-control at about $0.2 \mathrm{kN} / \mathrm{s}$. The front face of each beams was painted with a dotted bi-chromatic pattern. High resolution pictures, perpendicular to the observed surface, were taken at each $5 \mathrm{kN}$ increment throughout the entire loading cycle to enable subsequent analysis using Digital Image Correlation (DIC).

\section{Analysis using DIC}

Two-dimensional DIC analysis was run using MatchID v2016.2 in the process described previously. The logarithmic Euler-Almansi strain tensor was computed using the LevenbergMarquardt routine and a bilinear quadrilateral method of interpolation (Lava et al. 2016). Fig. 7ac shows the principal tensile strains contour map at condition of incipient failure on specimens I.1, II.1, and III.1. These are particularly useful to identify the location and distributions of cracks in the concrete.

\section{Predictions}

Flexural and shear failure load predictions based on the provisions of ACI 440.1R (2015), CSA S6 (2014) and CSA S806 (2012) for the three series of beam are reported in Table 6. The application of the formulas for flexural and shear capacity according to the above mentioned standards are reported in Tables 7 and 8.

Mean values for the concrete cylinder compressive strength (see previous sub-section) and W-FRP tensile ultimate strain and modulus of elasticity were obtained from experimental data; the FRP longitudinal bar ultimate strain and tensile modulus of elasticity were taken from manufacturer's data. All safety factors and environmental reduction factors are set equal to 1.0 for the purposes of 
these predictions. In this view, the experimental-to-predicted capacity ratios are expected to be equal or slightly greater than 1.0 while values significantly higher than 1.0 are to be considered overly conservative. Although the (ACI 440.1R 2015) introduces an environmental reduction factor for various fibre types and exposure conditions $\left(C_{E}\right)$, this shall be considered equal to 1.0 for carbon fibres exposed to standard conditions.

Since two orders of shear reinforcement with different inclinations to the beam axis need to be considered, Eq. (4) can be generalized under the simple assumption that $f_{f b}$ is the design stress at failure in both diagonal and vertical reinforcement legs, Eq. (9):

$$
V_{f}=\sum_{i=1}^{2} \frac{A_{f w, i} f_{f b} d_{w}\left(\cot \theta+\cot \beta_{i}\right) \sin \beta_{i}}{s_{i}}
$$

As stated by Stratford and Burgoyne (2003), the assumption that all of the FRP shear reinforcement crossing a diagonal crack has equal stress at shear failure is not correct due to the brittle nature of FRP. However, no current FRP design guideline is able to address this issue, and it would be quite complex to include such considerations in a design equation.

As shown in Table 6, Set I was designed to fail in shear, Set II was designed to fail in shear at a higher capacity provided by the wound reinforcement, and Set III was designed to provide the required shear strength to cause an over reinforced flexural failure.

\section{Results and Discussion}

The experimental capacity (total applied load), failure mode, and experimental-to-predicted capacity ratios are reported in Table 9 for all beams (full data can be viewed in the data archive, see data access statement for details). The specimens all failed in the expected manner, and the results obtained were consistent.

The load/mid-span deflection diagrams obtained from all beams are reported in Fig. 8. The 
experimental curves on sets II and III show a progressive reduction of the members' stiffness with increasing load, likely due to the local debonding of FRP longitudinal reinforcement and shear cracking in addition to softening of compressed concrete.

The load-strains diagrams measured on beams II.1, II.2, III.1, and III.2 shear reinforcement are reported in Fig. 8. The maximum values of strains, normally attained in correspondence of the beam failure, are indicated along with each of the curves.

The post-cracking behaviour showed by the carbon shear reinforcement is clearly distinguishable from that observed before the shear cracks took place. The only exception is seen in USG1 in specimen II.1 and USG2 in specimen III.2, which were mounted on shear legs that did not intercept any major shear cracks during the tests. It may also be pointed out that two of the strain gauges stopped working before beam failure, probably due to the high cracks that caused the severing of cables. In detail, the gauge USG3 mounted on specimen II.1 failed at $69 \%$ of the beam capacity, whereas the gauge USG2 mounted on specimen III.1 failed at $92 \%$ of the beam capacity.

Figs. 9 shows that strains measured in Set II specimens (Figs. 9a and 9b) after shear cracks took place are systematically higher than ones observed, for the same load, in Set III specimens (Figs. $9 \mathrm{c}$ and 9d). These higher strains are due to the reduced shear reinforcement ratio and result in wider shear cracks. Fig. 8 additionally shows that reductions in flexural stiffness with increasing load are much more evident in Set II than in Set III, even though all specimens have the same flexural properties. Therefore the additional deflection observed in Set II compared to Set III may largely be attributed to higher shear deformability.

\section{$\underline{\text { Set I }}$}

Beams without shear reinforcement (Set I) all exhibited a sudden diagonal tension failure. The DIC performed on specimen I.1 (Fig. 7.a) clearly shows a strain concentration in the specific 
diagonal crack that caused the collapse of the beams. Predictions (Table 6) given by both the ACI 440.1R (2015) and the CSA S6 (2006) formulation are largely on the safe side, with the first being less accurate than the latter. CSA S806 (2012) gives a slightly unsafe prediction in two cases but on average is the most accurate, with average experimental-to-theoretical ratio for shear failures of 0.94 compared to 1.35 for CSA S6 and 1.78 for ACI. It should also be noted that all of these values would be much larger if safety factors had been included.

\section{$\underline{\text { Set II }}$}

Set II demonstrates the additional shear strength provided by 3 layers of wound CFRP reinforcement. The beams again exhibited a diagonal tension failure, although in this case it was subsequent to the failure in the bends of the shear reinforcement. The shear capacity of the beams increased on average by $208 \%$, and a shear deformation regime was largely distributed on the entire structural element rather than in a single crack, as shown by analysis using DIC (Fig. 7.b). All the code provisions significantly underestimated the actual capacity of the beams, with CSA S6 (2006) giving the most conservative results (Table 9). In detail, they failed to predict accurately the limiting stress that can be achieved in bent CFRP strips as shear reinforcement. The load-strains data measured on Specimen II.2 (Figure 9.b) are particularly significant because the main diagonal cracks that caused the beam failure crossed the three legs about where strain gauges were installed, consequently it is possible to claim that ultimate strains at the sectional shear failure were measured.

The ratio between the ultimate strain measured on the diagonal links and the results of tensile tests on straight reinforcement (WT) is in line with the value that can be predicted using Eq. (2):

$$
\frac{f_{f b}}{f_{f u}}=\left(0.02 \frac{r_{b}}{d_{f i}}+0.47\right)=0.54
$$

where: 
$r_{b}$ is assumed equal to $5 \mathrm{~mm}$, and

$$
d_{f i}=\frac{2}{\sqrt{\pi}} t_{f}=\frac{2}{\sqrt{\pi}} 1.3 \mathrm{~mm}=7.8 \mathrm{~mm}
$$

\section{$\underline{\text { Set III }}$}

The beams in Set III all failed in flexure due to concrete crushing, at higher loads than expected. Average capacity ratios are equal to 1.49 and 1.41 , according to the ACI 440.1R (2015) and CSA CSA S806 (2012), respectively. DIC analysis (Fig. 7c) shows a shear deformation regime largely distributed on the entire structural element, however this is accompanied by a concentration of compressive strains at the top concrete of mid-span section.

The over resistance exhibited by the Set III beams may be explained by the following reasons:

- Due to local debonding of the longitudinal reinforcement, the plane sections hypothesis no longer holds in regimes of high flexural stresses. For this reason, the strains at failure in the longitudinal reinforcement are higher than predicted by simply applying a compatibility equation based on an assumption of plane sections remaining plane.

- As FRP longitudinal reinforcement is linear elastic up to failure, higher strains correspond to higher forces that must be equilibrated by the resultant force in the compressed concrete.

- Although the internal lever arm decreases (due to the neutral axis lowering), the internal forces increase more rapidly. Consequently, this may lead to a higher sectional capacity.

According to this rationale, the bending moment computed under the conventional perfect bonding assumption and the hypothesis of failure mode due to crushing, represents a lower bound value of the actual flexural capacity, hence it provides an appropriate and conservative method of computation.

The average experimental failure load of $149.8 \mathrm{kN}$ requires the achievement of a $1.25 \%$ strain in 
the longitudinal reinforcement at ultimate, which is compatible with the $1.75 \%$ ultimate strain of the CFRP bars.

The maximum strains attained in the shear reinforcement at failure are high $(0.49 \%$ in the diagonal legs for both specimen III.1 and III.2, as shown in Fig. 9c and 9d), with this circumstance demonstrating that the wound reinforcement capacity was extensively exploited in order to increase the shear capacity of the beams.

\section{CONCLUSIONS}

The possibility of manufacturing a bespoke shear reinforcement for optimized concrete beams by winding carbon fibres around a bundle of FRP reinforcing bars has been analysed in this paper.

The two methods of wet- and dry- winding were considered, with characterization tests conducted to determine relevant mechanical properties of the FRP wound reinforcement. The effectiveness of the material as shear reinforcement for concrete members was subsequently established by through four point bending tests performed on beams.

The results of the study support the following conclusions:

1. A novel gripping method for performing tensile tests on a straight portion of wound reinforcement was developed. Whereas the obtained modulus of elasticity was in line with expected results, the failure load was always lower than what could be expected according to fibre content alone.

2. The results obtained on bent reinforcement show that the use of wound CFRP in lieu of conventional circular CFRP stirrups not only offers advantages in terms of construction flexibility at more affordable costs, but can also help to mitigate the reduction of the strength due to bent corners.

3. The economical and practical advantages offered by the wet-wound reinforcement and its 
apparent enhanced efficiency at bent corners, seems to make it preferable to the dry-wound reinforcement for the fabrication of shear reinforcement cages.

4. It is possible to provide shear reinforcement in concrete beams by winding CFRP reinforcement around the longitudinal bars.

5. The existing FRP provisions can be used to predict the shear strength of W-FRP prismatic beams, provided the actual strength of FRP at bent corners and a good estimate of the angle of inclined concrete struts is known.

6. The value of strains observed on different shear links intersecting the same cracked section appears substantially uniform and in agreement with the value that can be predicted using the Equation proposed by Lee et al. (2014).

\section{ACKNOWLEDGEMENTS}

This work is funded by the Engineering and Physical Sciences Research Council under grant EP/M01696X/1. The first author acknowledges the J. William Fulbright Foreign Scholarship Board for the opportunity of developing part of this research at the University of Miami.

\section{DATA ACCESS STATEMENT}

All data created during this research are openly available from the University of Bath data archive at http://doi.org/10.15125/BATH-00204. 


\section{REFERENCES}

AASHTO LRFD (2009). "Bridge design guide specifications for GFRP-reinforced concrete bridge decks and traffic railings." American Association of State Highway and Transportation Officials, Washington, DC.

ACI 440.1R (2015). "Guide for the Design and Construction of Structural Concrete Reinforced with Fiber-Reinforced Polymer (FRP) Bars." American Concrete Institute, Farmington Hills, MI.

ACI 440.3R (2012). "Guide Test Methods for Fiber-Reinforced Polymers (FRPs) for Reinforcing or Strengthening Concrete Structures." American Concrete Institute, Farmington Hills, MI.

ACI 440R (2007). "Report on Fiber-Reinforced Polymer (FRP) Reinforcement for Concrete Structures." American Concrete Institute, Farmington Hills, MI.

Ahmad, S. (2003). "Reinforcement corrosion in concrete structures, its monitoring and service life prediction - A review." Cement and Concrete Composites, 25(4-5 SPEC), 459-471.

Ali, A., Mohamed, H., and Benmokrane, B. (2016). "Shear Behavior of Circular Concrete Members Reinforced with GFRP Bars and Spirals at Shear Span-to-Depth Ratios between 1.5 and 3.0." J Compos Constr, American Society of Civil Engineers, 04016055.

Ascione, L., Razaqpur, A. G., and Spadea, S. "Effectiveness of FRP stirrups in concrete beams subject to shear." Proc., 7th International Conference on FRP Composites in Civil Engineering (CICE 2014)Vancouver (Canada).

Bamforth, P., Chisholm, D., Gibbs, J., and Harrison, T. (2008). Properties of concrete for use in Eurocode 2, The Concrete Centre, Camberley, Surrey, UK.

Boden, T. A., Marland, G., and Andres, R. J. (2013). "Global, Regional, and National Fossil-Fuel CO2 Emissions." Carbon Dioxide Information Analysis Center (CDIAC), Oak Ridge 
National Laboratory, U.S. Department of Energy, Oak Ridge, Tenn., USA.

CNR-DT 203 (2006). "Guide for the design and construction of concrete structures with fiberreinforced polymer bars." National Research Council, Rome, Italy.

CSA S6 (2014). "Canadian Highway Bridge Design Code." Canadian Standard Association, Toronto, Ontario, Canada.

CSA S806 (2012). "Design and Construction of Buildings Components with Fiber-Reinforced Polymers." Canadian Standard Association, Toronto, Ontario, Canada.

EN ISO 527-1 (2012). "Plastics - Determination of tensile properties " Part 1: General principles, International Organization for Standardization, Geneva, Switzerland.

EN ISO 527-5 (2009). "Plastics - Determination of tensile properties " Part 5: Test conditions for unidirectional fibre-reinforced plastic composites, International Organization for Standardization, Geneva, Switzerland.

fib Bulletin 40 (2007). "FRP reinforcement in RC structures. International Federation for Structural Concrete." Fédération Internationale du Béton, Lausanne, Switzerland.

Hoult, N. A., Sherwood, E. G., Bentz, E. C., and Collins, M. P. (2008). "Does the use of FRP reinforcement change the one-way shear behavior of reinforced concrete slabs?" J Compos Constr, 12(2), 125-133.

Hughes Brothers (2011). "Aslan 200 Carbon Fiber Reinforced Polymer (CFRP) Bar - Product Data Sheet." < $\underline{\text { http://www.aslanfrp.com/Media/Aslan200 datasheet.pdf }>}$.

Ishihara, K., Obara, T., Sato, Y., Ueda, T., and Kakuta, Y. "Evaluation of ultimate strength of FRP rods at bent-up portion." Proc., Int. Symp. on Nonmetallic (FRP) Reinforcement for Concrete Structures Japan Concrete Institute, 7-34.

IUPAC (2014). "Compendium of Chemical Terminology - the Gold Book." 
$<\underline{\text { http://goldbook.iupac.org/PDF/goldbook.pdf }>}$.

JSCE (1997). "Design guidelines of FRP reinforced concrete building structures." Concrete engineering series no. 23, Japan Society of Civil Engineers, Tokyo, Japan.

Lava, P., Debruyne, D., Pierron, F., and Wittevrongel, L. (2016). "Match ID 2016.2 User Manual ", $<$ http://matchidmbc.be/>.

Lee, C., Ko, M., and Lee, Y. (2014). "Bend Strength of Complete Closed-Type Carbon FiberReinforced Polymer Stirrups with Rectangular Section." J Compos Constr, 18(1).

Maruyama, T., Honama, M., and Okamura, H. (1993). "Experimental study on tensile strength of bent portion of FRP rods." ACI Special publication, SP-138, 163-176.

Nanni, A. (1993). Fiber-reinforced-plastic for concrete structures: Properties and applications, Elsevier Science, Amsterdam.

Orr, J. J., Darby, A., Ibell, T., and Evernden, M. (2014). "Design methods for flexibly formed concrete beams." ICE Structures and Buildings, 167(SB1), 1-13.

Pan, B., Qian, K., Xie, H., and Asundi, A. (2009). "Two-dimensional digital image correlation for in-plane displacement and strain measurement: A review." Measurement Science and Technology, 20(6).

Plecnik, J., and Ahmad, S. H. (1988). "Transfer of composite technology to design and construction of bridges." Final report to US DOT, contract no. DTRS 5683-C000043.

Razaqpur, A. G., and Isgor, O. B. (2006). "Proposed shear design method for FRP-reinforced concrete members without stirrups." ACI Structural Journal, 103(1), 93-102.

Razaqpur, A. G., and Spadea, S. (2015). "Shear Strength of FRP Reinforced Concrete Members with Stirrups." J Compos Constr, 19(1).

Said, M., Adam, M. A., Mahmoud, A. A., and Shanour, A. S. (2016). "Experimental and analytical 
shear evaluation of concrete beams reinforced with glass fiber reinforced polymers bars." Construction and Building Materials, 102, 574-591.

Shehata, E., Morphy, R., and Rizkalla, S. (2000). "Fibre reinforced polymer shear reinforcement for concrete members: behaviour and design guidelines." Can J Civil Eng, 27(5), 859-872.

Stratford, T., and Burgoyne, C. (2003). "Shear analysis of concrete with brittle reinforcement." $J$ Compos Constr, 7(4), 323-330.

Thirion, C. (2012). "Putting the material in the right place: Investigations into the sustainable use of structural materials to reduce the initial embodied environmental impact of building structures." MPhil, University College London, London.

Tureyen, A. K., and Frosch, R. J. (2003). "Concrete Shear Strength: Another Perspective." Structural Journal, 100(5).

Vecchio, F. J., and Collins, M. P. (1986). "Modified Compression-Field Theory for Reinforced Concrete Elements Subjected to Shear." Journal of the American Concrete Institute, 83(2), 219-231. 
Table 1. Properties of the carbon fibres employed

\begin{tabular}{cc}
\hline Property & C T50-4.0/240-E100 \\
\hline Number of Filaments & $50 \mathrm{k}$ \\
Filament diameter & $7 \mu \mathrm{m}$ \\
Tensile Strength $\left(f_{f c, u}\right)$ & $4000 \mathrm{MPa}$ \\
Tensile Modulus $\left(E_{c f}\right)$ & $240 \mathrm{GPa}$ \\
Elongation at break $\left(\varepsilon_{c f, u}\right)$ & $1.7 \%$ \\
Density $\left(\rho_{c f}\right)$ & $1800 \mathrm{~kg} / \mathrm{m}^{3}$ \\
Sizing Compatibility & Epoxy \\
\hline
\end{tabular}


Table 2. Properties of the epoxy resins, curing methods employed, and measured volume fraction

\begin{tabular}{ccc}
\hline Property & Wet Winding & Dry Winding \\
\hline Epoxy Resin & Fyfe S & UF3369 \\
Tensile Strength $\left(f_{r, u}\right)$ & $72.4 \mathrm{MPa}$ & $92.4 \mathrm{MPa}$ \\
Tensile Modulus $\left(E_{r}\right)$ & $3.2 \mathrm{GPa}$ & $3.1 \mathrm{GPa}$ \\
Elongation at break $\left(\varepsilon_{r, u}\right)$ & $5.0 \%$ & $3.6 \%$ \\
Curing Method & $72 \mathrm{~h}, 21^{\circ} \mathrm{C}$ & $4 \mathrm{~h}, 120^{\circ} \mathrm{C}(\mathrm{vacuum})$ \\
Density $\left(\rho_{r}\right)$ & $1100 \mathrm{~kg} / \mathrm{m}^{3}$ & $1180 \mathrm{~kg} / \mathrm{m}^{3}$ \\
Fiber volume fraction $\left(\mathrm{VF}_{\mathrm{f}}\right)$ & 0.45 & 0.60 \\
Resin volume fraction $\left(\mathrm{VF}_{\mathrm{r}}\right)$ & 0.55 & 0.40 \\
\hline
\end{tabular}


Table 3. Geometrical properties of the CFRP samples

\begin{tabular}{cccccccc}
\hline Manufacturing Technique & $\begin{array}{c}A_{c f} \\
\mathrm{~mm}^{2}\end{array}$ & $\begin{array}{c}A_{r} \\
\mathrm{~mm}^{2}\end{array}$ & $\begin{array}{c}A_{f} \\
\mathrm{~mm}^{2}\end{array}$ & $\begin{array}{c}r_{b} \\
\mathrm{~mm}\end{array}$ & $\begin{array}{c}d_{f e} \\
\mathrm{~mm}\end{array}$ & $\begin{array}{c}w_{f} \\
\mathrm{~mm}\end{array}$ & $\begin{array}{c}t_{f e} \\
\mathrm{~mm}\end{array}$ \\
\hline \multirow{2}{*}{ Wet Wound Stirrups } & 15.4 & 18.8 & 34.2 & 15.0 & 6.6 & 15.0 & 2.3 \\
& & & & & & 25.0 & 1.4 \\
\hline & & & & & & 6.0 & 4.3 \\
Pre-preg Wound Stirrups & 15.4 & 10.3 & 25.7 & 15.0 & 5.7 & 15.0 & 1.7 \\
& & & & & & 25.0 & 1.0 \\
\hline
\end{tabular}


Table 4. Results of tensile tests

\begin{tabular}{|c|c|c|c|c|c|c|c|c|}
\hline \multirow{2}{*}{ Set of Specimens } & & \multicolumn{2}{|c|}{$\begin{array}{c}25 \% \text { Failure } \\
\text { Load }\end{array}$} & \multicolumn{2}{|c|}{$\begin{array}{c}50 \% \text { Failure } \\
\text { Load }\end{array}$} & \multicolumn{2}{|c|}{$\begin{array}{c}100 \% \text { Failure } \\
\text { Load }\end{array}$} & \multirow{2}{*}{$\begin{array}{l}E_{C F R P} \\
(\mathrm{GPa})\end{array}$} \\
\hline & & $\begin{array}{l}F_{25 \%} \\
(\mathrm{kN})\end{array}$ & $\varepsilon_{25 \%}(\%)$ & $\begin{array}{l}F_{50 \%} \\
(\mathrm{kN})\end{array}$ & $\varepsilon_{50 \%}(\%)$ & $F_{u}(\mathrm{kN})$ & $\varepsilon_{u}(\%)$ & \\
\hline \multirow{3}{*}{$\begin{array}{c}\text { Wet-Wound } \\
\text { Reinforcement }(\mathrm{WT}) \\
(5 \text { specimens })\end{array}$} & Mean & 12.0 & 0.35 & 23.9 & 0.68 & 47.9 & 1.29 & 142.0 \\
\hline & $\mathrm{SD}$ & 0.74 & 0.03 & 1.48 & 0.05 & 2.97 & 0.07 & 3.97 \\
\hline & $\mathrm{COV}$ & $6 \%$ & $8 \%$ & $6 \%$ & $7 \%$ & $6 \%$ & $5 \%$ & $3 \%$ \\
\hline \multirow{3}{*}{$\begin{array}{c}\text { Dry-Wound } \\
\text { Reinforcement (DT) } \\
\text { (5 specimens) }\end{array}$} & Mean & 12.0 & 0.35 & 23.9 & 0.68 & 47.9 & 1.29 & 142.0 \\
\hline & SD & 0.74 & 0.03 & 1.48 & 0.05 & 2.97 & 0.07 & 3.97 \\
\hline & $\mathrm{COV}$ & $6 \%$ & $8 \%$ & $6 \%$ & $7 \%$ & $6 \%$ & $5 \%$ & $3 \%$ \\
\hline
\end{tabular}


Table 5. Results of the push-off tests

\begin{tabular}{|c|c|c|c|c|c|c|c|c|c|}
\hline \multirow[t]{2}{*}{ Specimen } & \multirow[t]{2}{*}{$w_{f} / t_{f}$} & \multirow{2}{*}{$\begin{array}{c}F_{b} \\
(\mathrm{kN})\end{array}$} & \multicolumn{3}{|c|}{$f_{b} / f_{u}$} & \multirow{2}{*}{$\begin{array}{c}\varepsilon_{1} \\
(\%) \\
\end{array}$} & \multirow{2}{*}{$\begin{array}{c}\varepsilon_{2} \\
(\%) \\
\end{array}$} & \multirow{2}{*}{$\frac{\varepsilon_{1}+\varepsilon_{2}}{2 \varepsilon_{u}}$} & \multirow{2}{*}{$\begin{array}{c}\text { Failure } \\
\text { mode }\end{array}$} \\
\hline & & & Exp. & $\mathrm{ACI}$ & Lee et al. & & & & \\
\hline WB.06 & 1.1 & 50.2 & 0.56 & 0.41 & 0.52 & 0.708 & 0.816 & 0.610 & L2 \\
\hline WB. 15 & 6.5 & 76.5 & 0.85 & 0.41 & 0.59 & 1.169 & 1.012 & 0.872 & L1 \\
\hline WB. 25 & 17.9 & 75.3 & 0.84 & 0.41 & 0.66 & 1.051 & 1.131 & 0.873 & $\mathrm{~S}$ \\
\hline DB.06 & 1.4 & 44.3 & 0.46 & 0.43 & 0.53 & 0.380 & 0.640 & 0.408 & L2 \\
\hline DB. 15 & 8.8 & 51.9 & 0.54 & 0.43 & 0.63 & 0.770 & 0.480 & 0.500 & L1 \\
\hline DB. 25 & 25.0 & 65.8 & 0.69 & 0.43 & 0.74 & 0.910 & 0.700 & 0.644 & $\mathrm{~L} 1$ \\
\hline
\end{tabular}


Table 6. Flexural and Shear failure load predictions.

\begin{tabular}{ccccccccccc}
\hline & \multirow{2}{*}{$\begin{array}{c}\text { Set } \\
\text { CFRP }\end{array}$} & $A_{f w}$ & \multirow{2}{*}{$\begin{array}{c}w_{f} \\
\text { layers }\end{array}\left(\mathrm{mm}_{f e}^{2}\right)$} & \multicolumn{3}{c}{ Flexural failure load $(\mathrm{kN})$} & \multicolumn{2}{c}{ Shear failure load $(\mathrm{kN})$} \\
\cline { 6 - 10 } & $(\mathrm{mm})$ & $(\mathrm{mm})$ & ACI 440 & CSA S6 & CSA S806 & ACI 440 & CSA S6 CSA S806 \\
\hline I & - & - & - & - & 100.2 & 106.2 & 106.2 & 21.9 & 28.8 & 41.4 \\
II & 3 & 12.8 & 10.0 & 1.3 & 100.2 & 106.2 & 106.2 & 76.0 & 55.1 & 84.0 \\
III & 8 & 34.2 & 10.0 & 2.9 & 100.2 & 106.2 & 106.2 & 166.3 & 111.8 & 155.0 \\
\hline
\end{tabular}


Table 7. Flexural Capacity Prediction

\section{ACI 440 (2015) and \\ CSA S806 (2012) and \\ ACI 318 (2014) \\ CSA S6 (2014)}

Equilibrium about the

compressed concrete centroid

$M_{r}=A_{f} f_{f}\left(d-\frac{\beta_{1} c}{2}\right)$

Equilibrium along the beam axis

$$
f_{f}=E_{f l} \varepsilon_{c u}\left(\frac{d}{c}-1\right)
$$

Strain compatibility

$$
c=\frac{A_{f} f_{f}}{\alpha_{1} \beta_{1} f_{c} b_{w}}
$$

$$
\begin{array}{cl}
\alpha_{1}=0.85 & \alpha_{1}=0.85-0.0015 f_{c} \\
-0.008\left(f_{c}-30 \mathrm{MPa}\right) & \beta_{1}=0.97-0.0025 f_{c}
\end{array}
$$

Concrete constitutive model

$$
\beta_{1}=0.85-0.008\left(f_{c}-30 \mathrm{MPa}\right)
$$

$$
\varepsilon_{c u}=0.003
$$$$
\varepsilon_{c u}=0.0035
$$

Resisting Moment

$M_{r}=24.4 \mathrm{kNm}$

$M_{r}=25.9 \mathrm{kNm}$

Maximum applicable Load

$2 P=100.2 \mathrm{kN}$

$2 P=106.2 \mathrm{kN}$ 
Table 8. Shear Capacity Predictions

Concrete Contribution $\left(V_{c}\right)$

$V_{c}=\frac{2}{5} \sqrt{f_{c}} b_{w}(k d)=10.9 \mathrm{kN}$

$k=\sqrt{2 \rho_{f} n_{f}+\left(\rho_{f} n_{f}\right)^{2}}-\rho_{f} n_{f}=0.22$

$n_{f}=\frac{E_{f l}}{E_{c}}=4.47$

$V_{c}=2.5 \beta \phi_{c} f_{c r} b_{w} d_{v}= \begin{cases}14.4 \mathrm{kN} & (\text { Set } 1) \\ 9.3 \mathrm{kN} & (\text { Set 2) } \\ 8.6 \mathrm{kN} & (\text { Set 3) }\end{cases}$

$f_{c r}=\min \left(0.4 \sqrt{f_{c}}, 3.2 \mathrm{MPa}\right)=2.4 \mathrm{MPa}$

$\beta=\left[\frac{0.4}{\left(1+1500 \varepsilon_{l}\right)}\right]\left[\frac{1300}{\left(1000+s_{z e}\right)}\right]$

$s_{z e}=\max \left(\frac{35 d_{v}}{\left(15+a_{g}\right)}, 0.85 d_{v}\right)=246 \mathrm{~mm}$

$a_{g}=10 \mathrm{~mm}$ (maximum aggregate size)
Shear reinforcement contribution $\left(V_{f}\right)$

ACI 440.1R (2015)

$$
\begin{aligned}
& V_{f}=\frac{A_{f w} f_{f w} d}{s}\left(1+\sin 45^{\circ}+\cos 45^{\circ}\right)= \begin{cases}27.1 \mathrm{kN} & (\text { Set } 2) \\
72.2 \mathrm{kN} & (\text { Set } 3)\end{cases} \\
& f_{f w}=\min \left(f_{f b}, 0.004 E_{C F R P, w}\right)=403 \mathrm{MPa}
\end{aligned}
$$

\section{CSA S6 (2014)}

$$
V_{f}=\frac{A_{f w} \phi_{F} f_{f w} d_{v}}{s}\left[\cot \theta+\left(\cot \theta+\sin 45^{\circ}+\cos 45^{\circ}\right)\right]=\left\{\begin{array}{l}
18.8 \mathrm{kN} \\
47.3 \mathrm{kN}
\end{array}\right.
$$

$$
f_{f w}=\min \left(f_{f b} / 1.5,0.004 E_{C F R P, w}\right)=\left\{\begin{array}{ll}
301 \mathrm{MPa} & (\text { Set 2) } \\
286 \mathrm{MPa} & (\text { Set 3 })
\end{array}\right\}
$$$$
\varepsilon_{l}=\frac{M_{a} / d_{v}+V_{a}}{2 E_{f l} A_{f l}} \leq 0.003
$$

$\theta=\left(30^{\circ}+7000 \varepsilon_{l}\right)\left(0.88+s_{z e} / 2500\right)= \begin{cases}44^{\circ} & (\text { Set 2) } \\ 44^{\circ} & (\text { Set 3) }\end{cases}$

\section{CSA S806 (2012)}

$V_{c}=0.05 \lambda \phi_{c} k_{m} k_{r}\left(f_{c}\right)^{1 / 3} b_{w} d_{v}=20.7 \mathrm{kN}$

$$
\begin{aligned}
& V_{f}=\frac{A_{f w} \phi_{F} f_{f w} d_{v}}{s}\left[\cot \theta+\left(\cot \theta+\sin 45^{\circ}+\cos 45^{\circ}\right)\right]=\left\{\begin{array}{l}
21.3 \mathrm{kN} \\
56.8 \mathrm{kN}
\end{array}\right. \\
& \varepsilon_{l}=\frac{M_{a} / d_{v}+V_{a}}{2 E_{f l} A_{f l}} f_{f w}=\min \left(0.4 f_{C F R P, w}, 0.005 E_{C F R P, w}\right)=504 \mathrm{MPa} \\
& \theta=\left(30^{\circ}+7000 \varepsilon_{l}\right) \leq 60^{\circ}= \begin{cases}60^{\circ} & (\text { Set 2) } \\
60^{\circ} & (\text { Set 3) }\end{cases}
\end{aligned}
$$

$0.11 \phi_{c}\left(f_{c}\right)^{1 / 2} b_{w} d_{v} \leq V_{c} \leq 0.22 \phi_{c}\left(f_{c}\right)^{1 / 2} b_{w} d_{v}$

$k_{m}=\min \left(\sqrt{V_{a} d / M_{a}}, 1\right)=0.63$

$k_{r}=1+\left(E_{l} \rho_{l}\right)^{1 / 3}=10.37$

Notes to CSA S6 and CSA S806 provisions:

- $\quad M_{a}$ and $V_{a}$ are the actual Bending Moment and Shear Force acting on a section located at a distance $a$ from the support. In this calculation $M_{a} /\left(V_{a} d\right)=2.5$ is considered.

- $\quad \varepsilon_{l}$ is the longitudinal strain at the mid-depth of the section.

- Partial factors for concrete and FRP are always set equal to 1.0 for the purpose of this prediction.

- $d_{v}=\min (0.9 d, 0.72 h)=176 \mathrm{~mm}$ is the effective shear depth.

- The computation of $V_{f}$ requires an iterative procedure to solve the following non linear equations:

- $V_{r}=V_{a}=V_{f}\left(V_{a}\right)+V_{c}\left(V_{a}\right)$

(CSA S6)

- $V_{r}=V_{a}=V_{f}\left(V_{a}\right)+V_{c}$

(CSA S806) 
Table 9. Experimental failure modes and loads

\begin{tabular}{cccccccc}
\hline \multirow{2}{*}{ Specimen } & \multicolumn{2}{c}{ Failure } & \multicolumn{2}{c}{ Experimental } & \multicolumn{3}{c}{ Experimental / Predicted ${ }^{\mathrm{c}}$ Ratio } \\
& Mode & Location $^{\mathrm{a}}$ & failure loads $(\mathrm{kN})$ & ACI 440 & CSA S6 & CSA S806 \\
\hline I.1 & Shear tension & side B & 38.3 & \multirow{2}{*}{$38.9^{\mathrm{b}}$} & 1.75 & 1.33 & 0.93 \\
I.2 & failure & side B & 39.6 & & 1.81 & 1.38 & 0.96 \\
\hline II.1 & \multirow{2}{*}{ Shear tension } & side B & 115.8 & \multirow{2}{*}{$120.1^{\mathrm{b}}$} & 1.52 & 2.10 & 1.38 \\
II.2 & and FRP rupture & side A & 124.3 & & 1.64 & 2.25 & 1.48 \\
\hline III.1 & \multirow{2}{*}{ Flexure } & mid-span & 149.2 & \multirow{2}{*}{$149.8^{\mathrm{b}}$} & 1.48 & 1.40 & 1.40 \\
III.2 & & mid-span & 150.3 & & 1.50 & 1.42 & 1.42 \\
\hline
\end{tabular}

${ }^{\mathrm{a}}$ Fig. $5 ;{ }^{\mathrm{b}}$ Average capacity per set $(\mathrm{kN}) ;{ }^{\mathrm{c}}$ See Table 8 for predicted capacity. 


\section{LIST OF FIGURES}

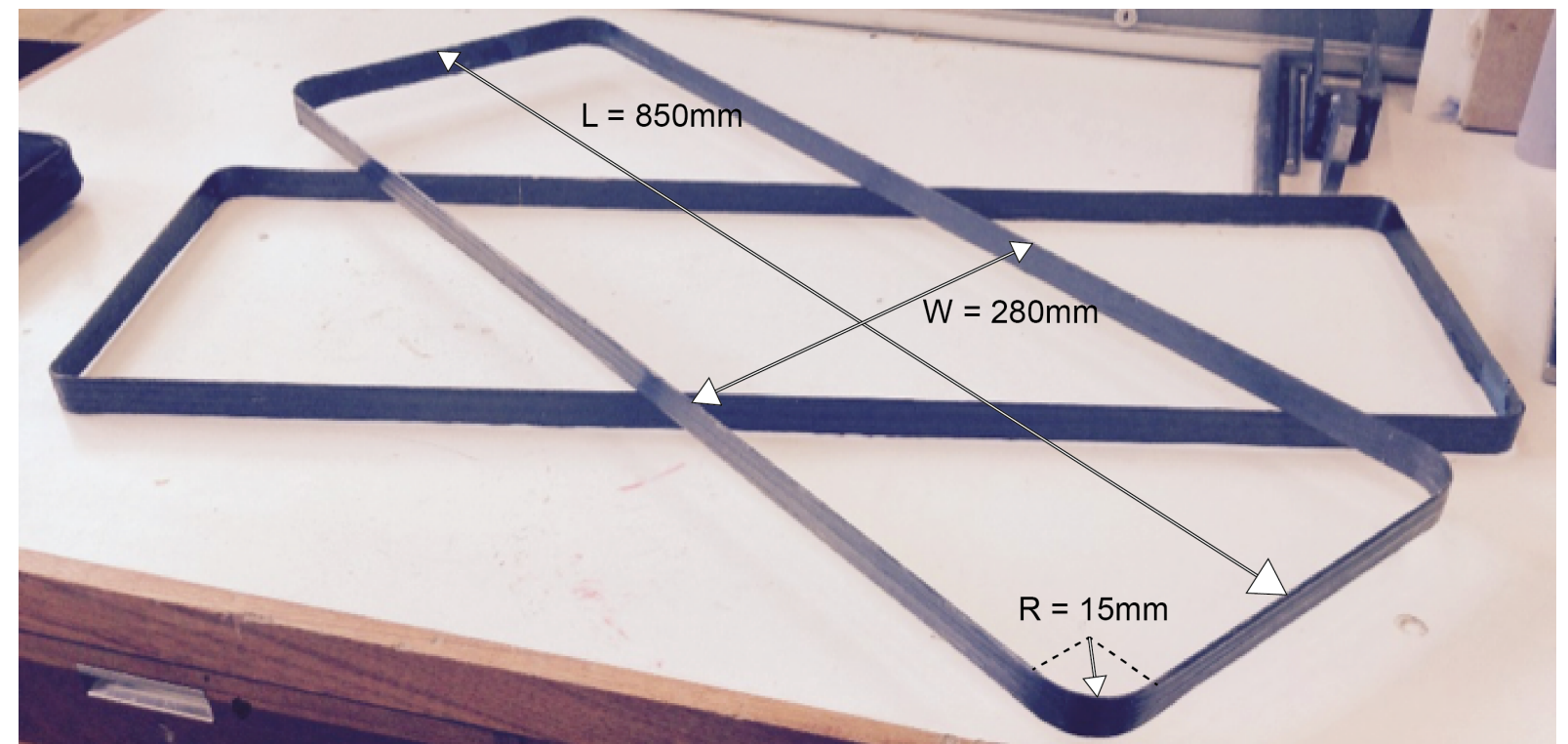

Fig. 1. CFRP stirrup samples utilised in Series 1 and Series 2
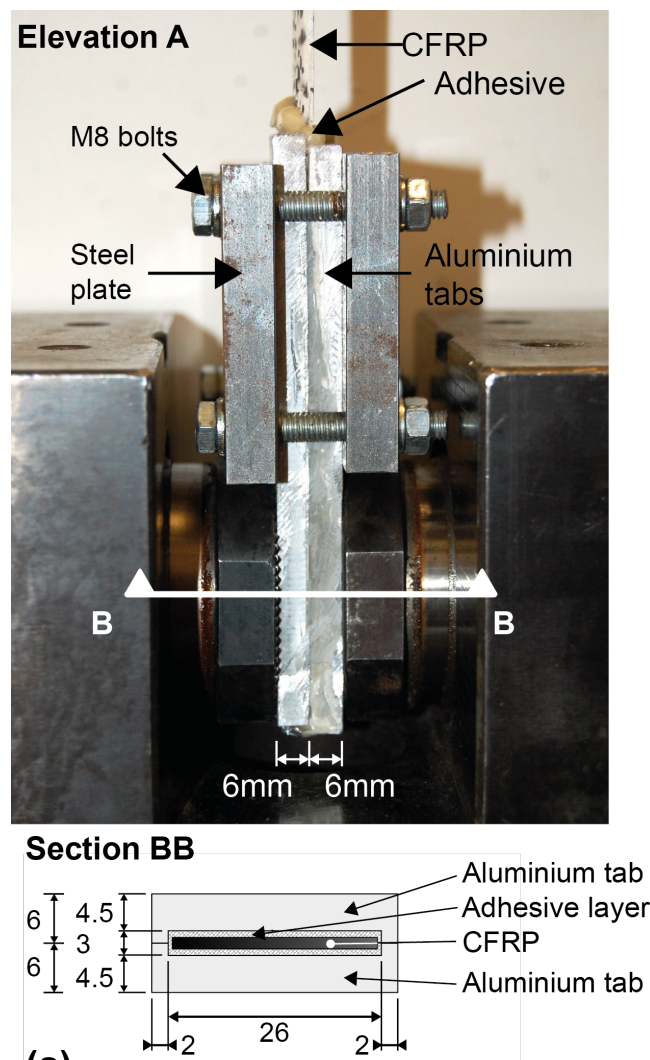

(a)
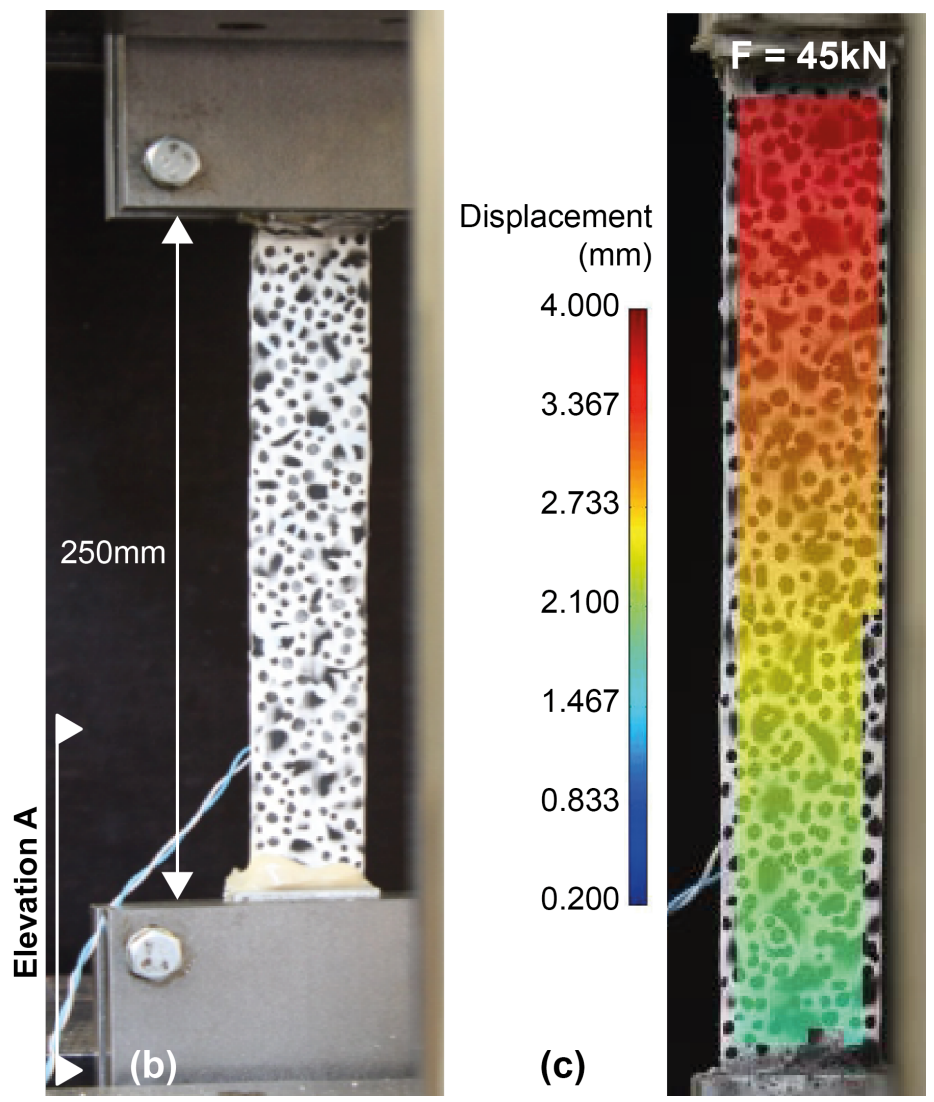

Fig. 2. CFRP tensile tests: a) gripping system; b) test setup; c) displacement contour map. 


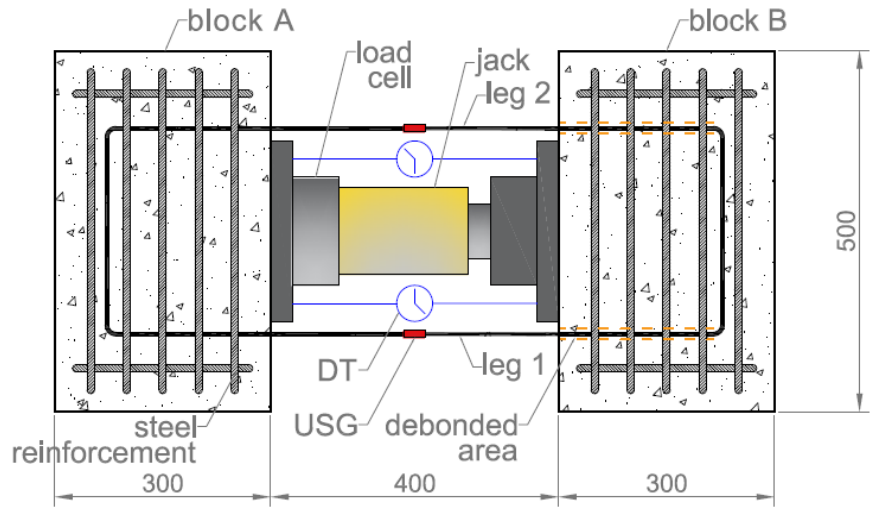

(a)

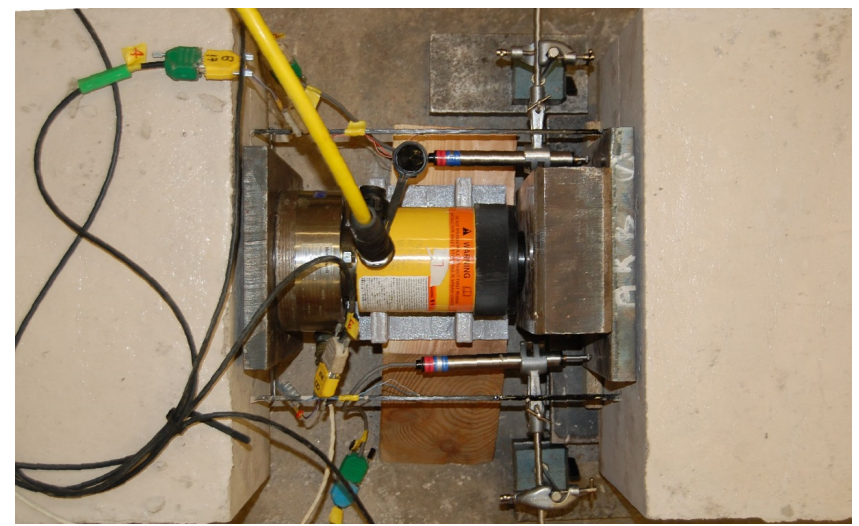

(b)

Fig. 3. Experimental tests on bent CFRP reinforcement: a) Layout; b) Test photo.

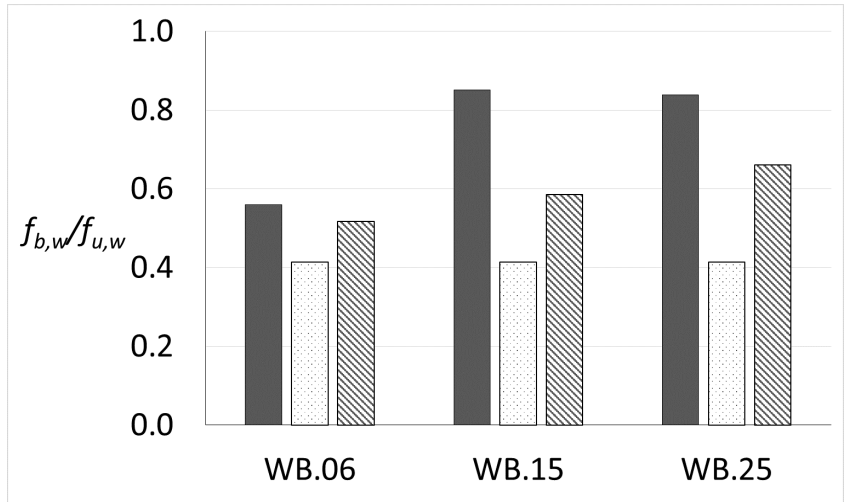

Exp. $\square \mathrm{ACl} 440$ (2015) $\mathbb{Q}$ Lee et al. (2014)

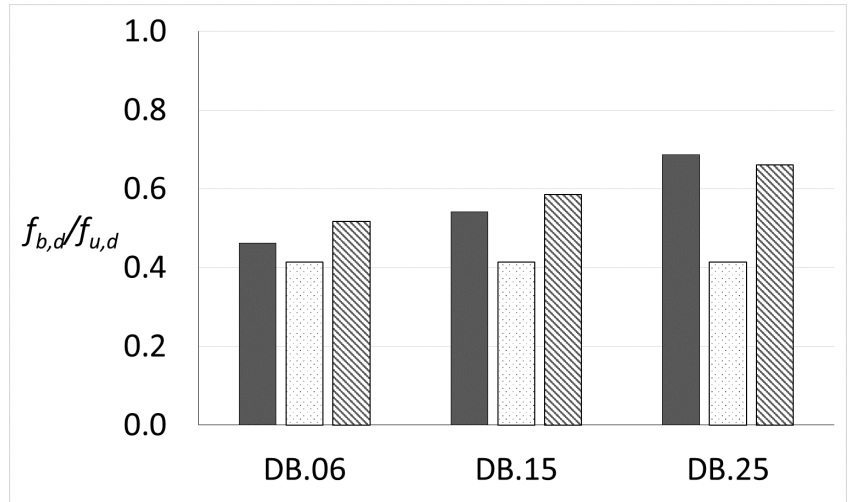

$\square$ Exp. $\square \mathrm{ACl} 440$ (2015) $\mathbb{Q}$ Lee et al. (2014)

(a)

(b)

Fig. 4. $f_{b} / f_{u}$ ratio: a) Wet wound reinforcement; b) Dry wound reinforcement. 


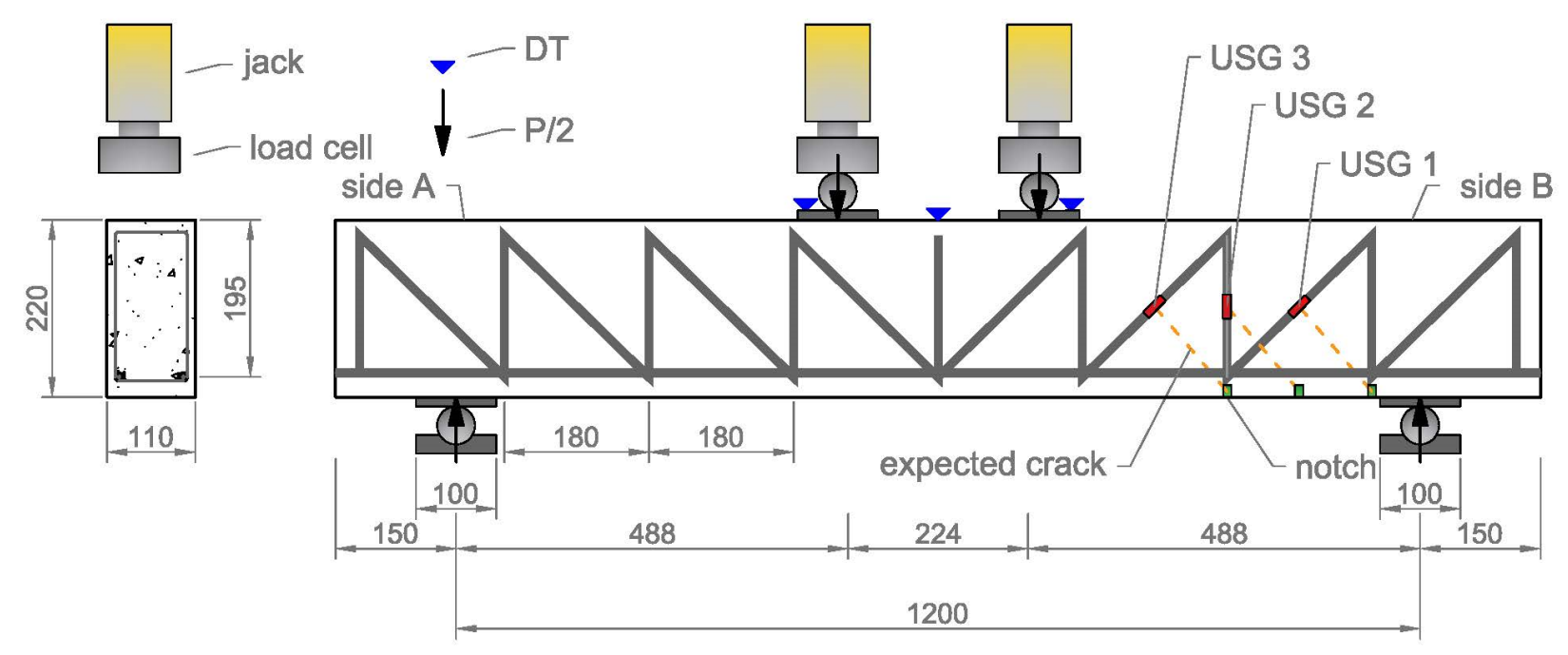

Fig. 5. Four Point bending test setup.

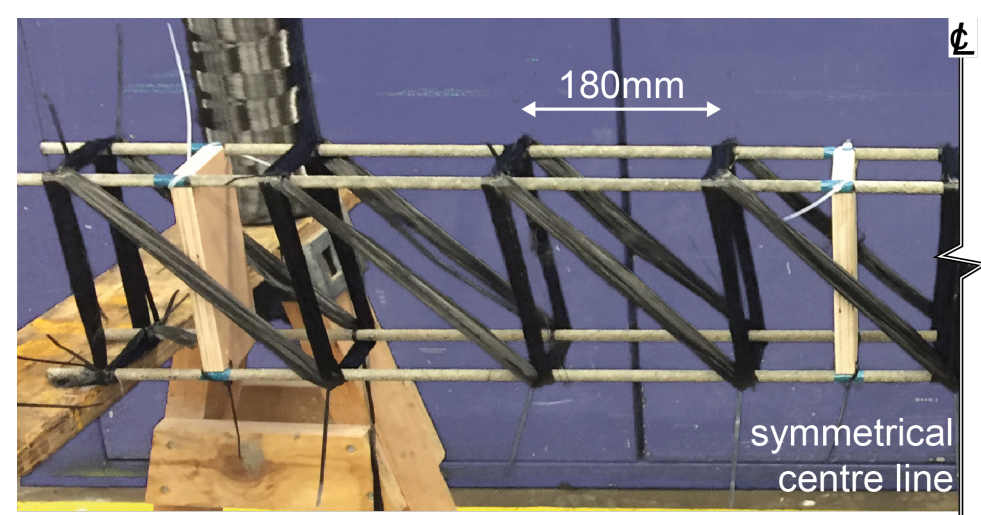

(a)

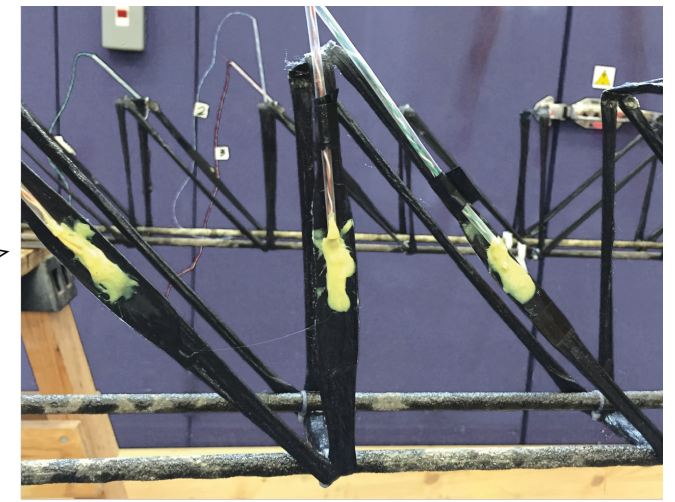

(b)

Fig. 6. CFRP reinforcing cage: (a) during winding; (b) after attaching strain gauges. 


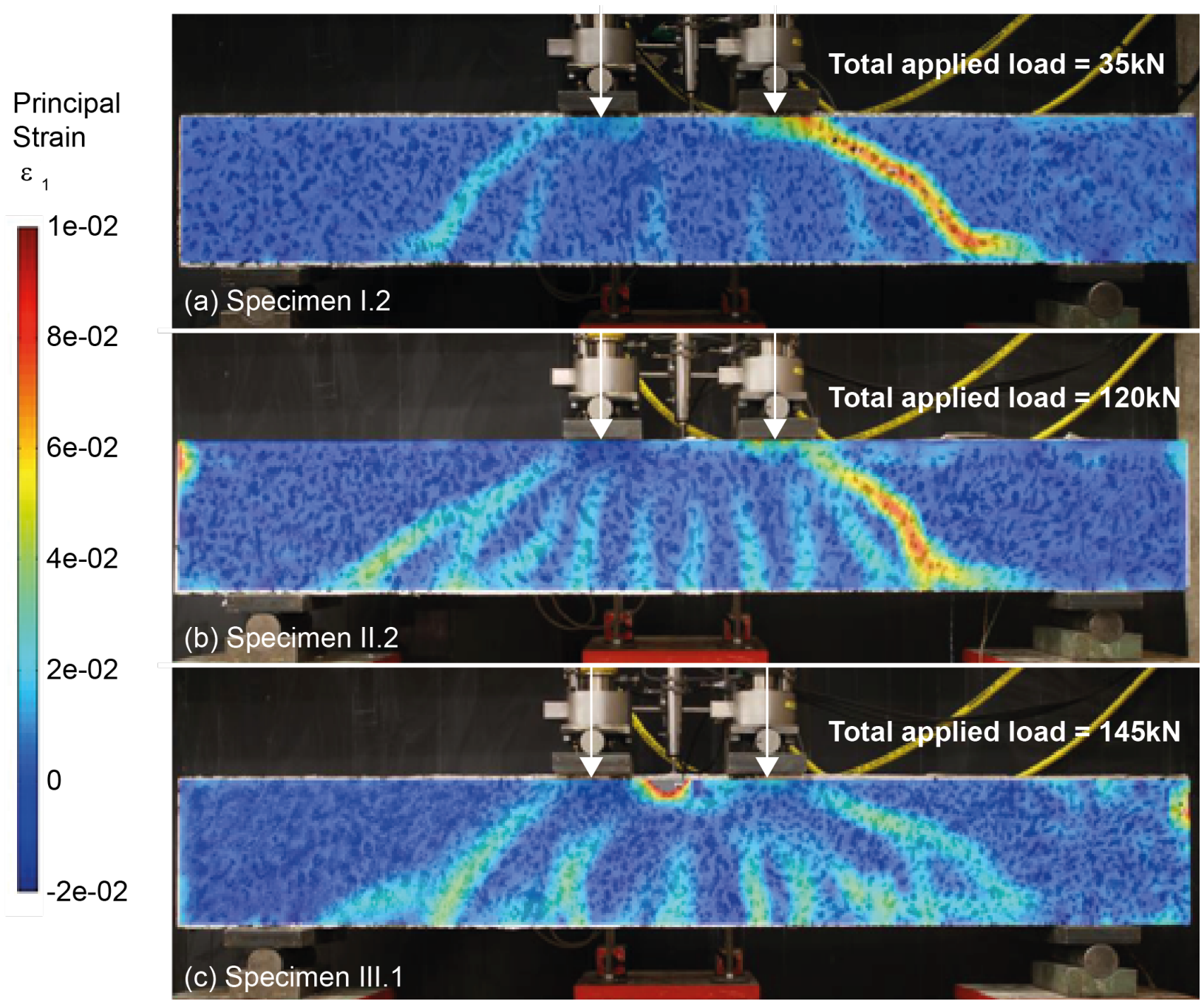

Fig. 7. Digital Image Correlation results showing principal strains at failure condition for (a) Specimen I.2; (b) Specimen II.2 and (c) Specimen III.1. 


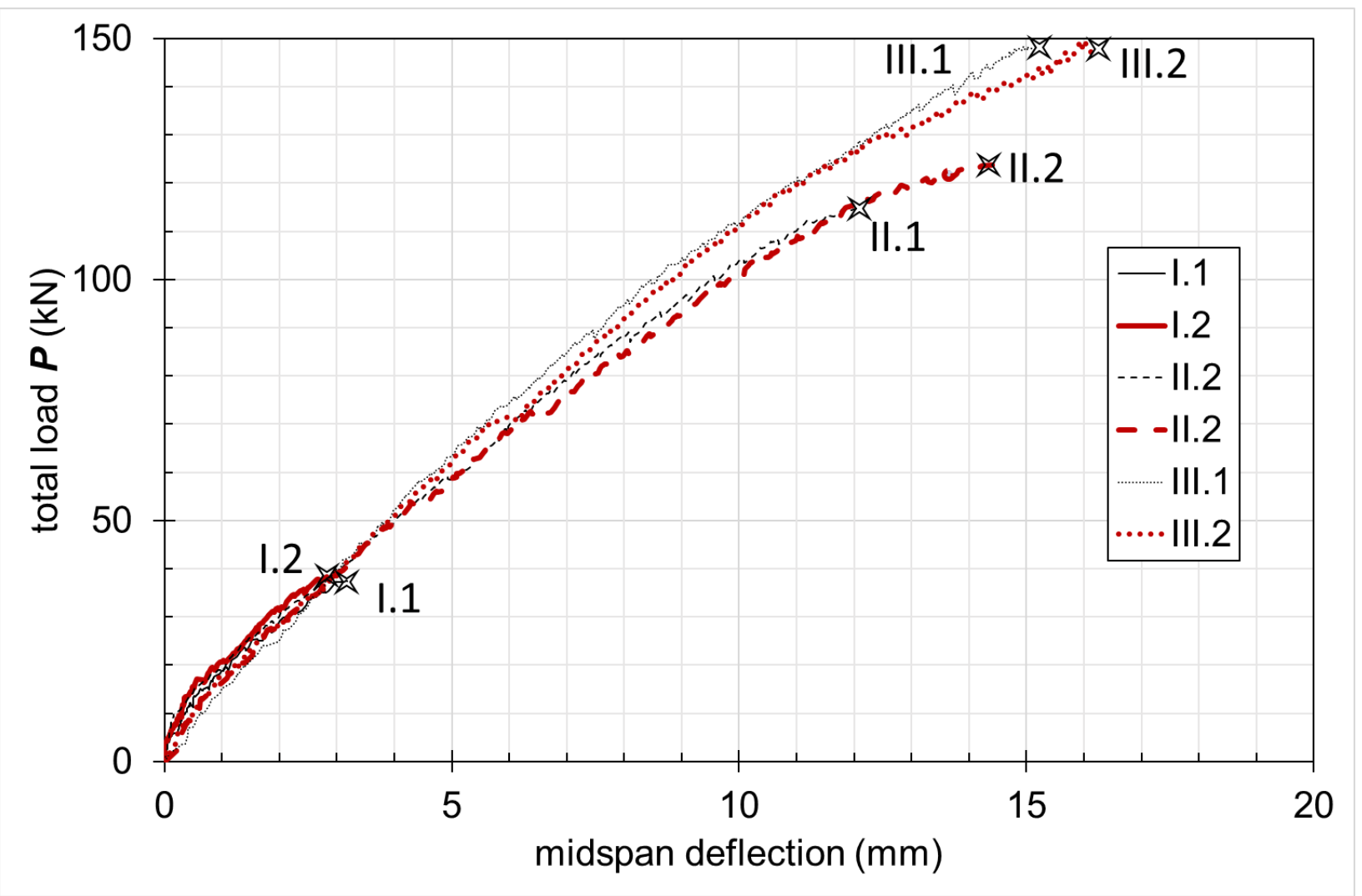

Fig. 8. Load vs. midspan deflection diagram for beam specimens 


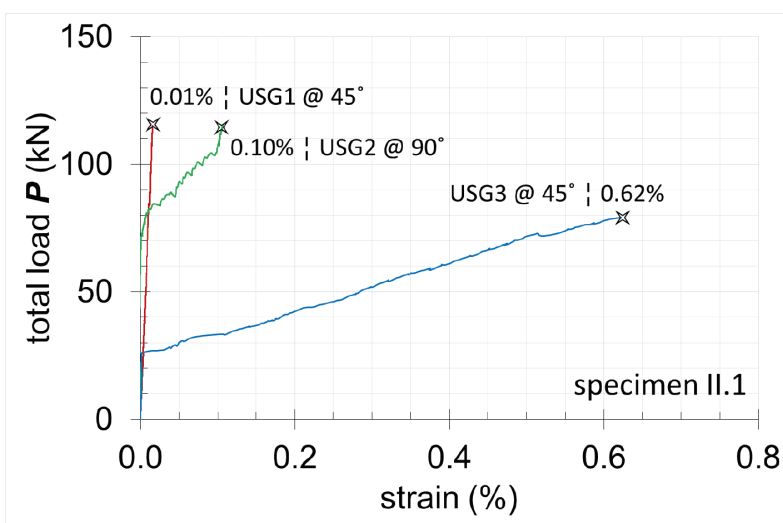

(a)

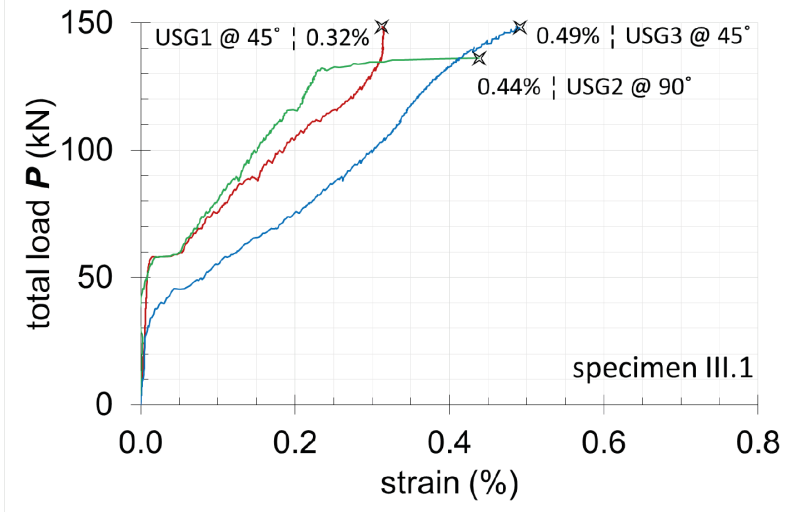

(c)

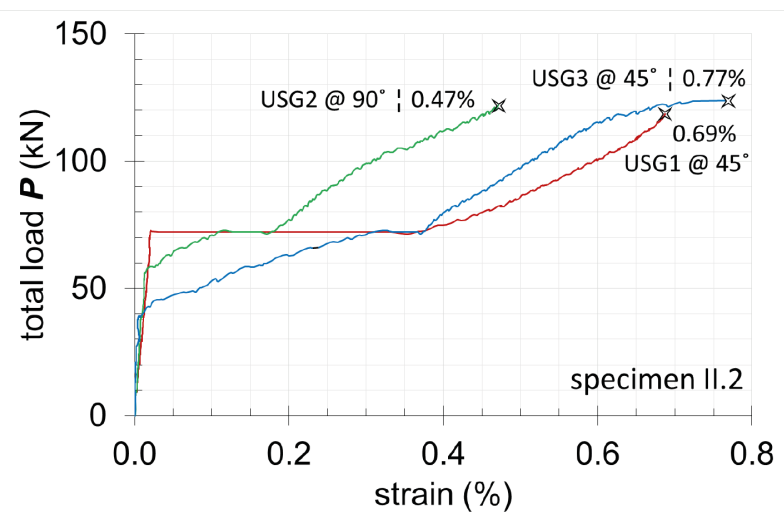

(b)

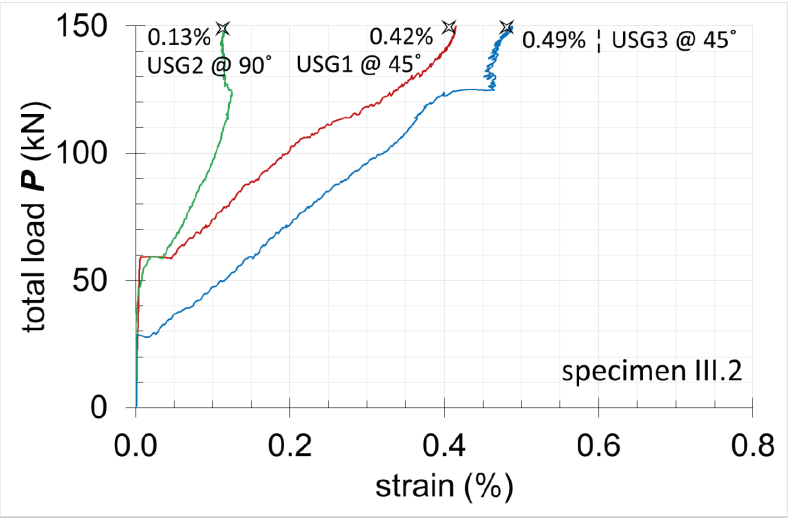

(d)

Fig. 9. Load vs. Strains diagram: a) Specimen II.1; b) Specimen II.2; c) Specimen III.1 and d) Specimen III.2. 